This item was submitted to Loughborough's Research Repository by the author.

Items in Figshare are protected by copyright, with all rights reserved, unless otherwise indicated.

\title{
Systems modelling approaches to the design of safe healthcare delivery: ease of use and usefulness perceived by healthcare worker
}

\section{PLEASE CITE THE PUBLISHED VERSION}

http://dx.doi.org/10.1080/00140139.2010.489653

\section{PUBLISHER}

(C) Taylor \& Francis

\section{VERSION}

AM (Accepted Manuscript)

\section{LICENCE}

CC BY-NC-ND 4.0

\section{REPOSITORY RECORD}

Jun, Gyuchan Thomas, James R. Ward, and P. John Clarkson. 2019. "Systems Modelling Approaches to the Design of Safe Healthcare Delivery: Ease of Use and Usefulness Perceived by Healthcare Worker". figshare. https://hdl.handle.net/2134/9547. 
This item was submitted to Loughborough's Institutional Repository (https://dspace.lboro.ac.uk/) by the author and is made available under the following Creative Commons Licence conditions.

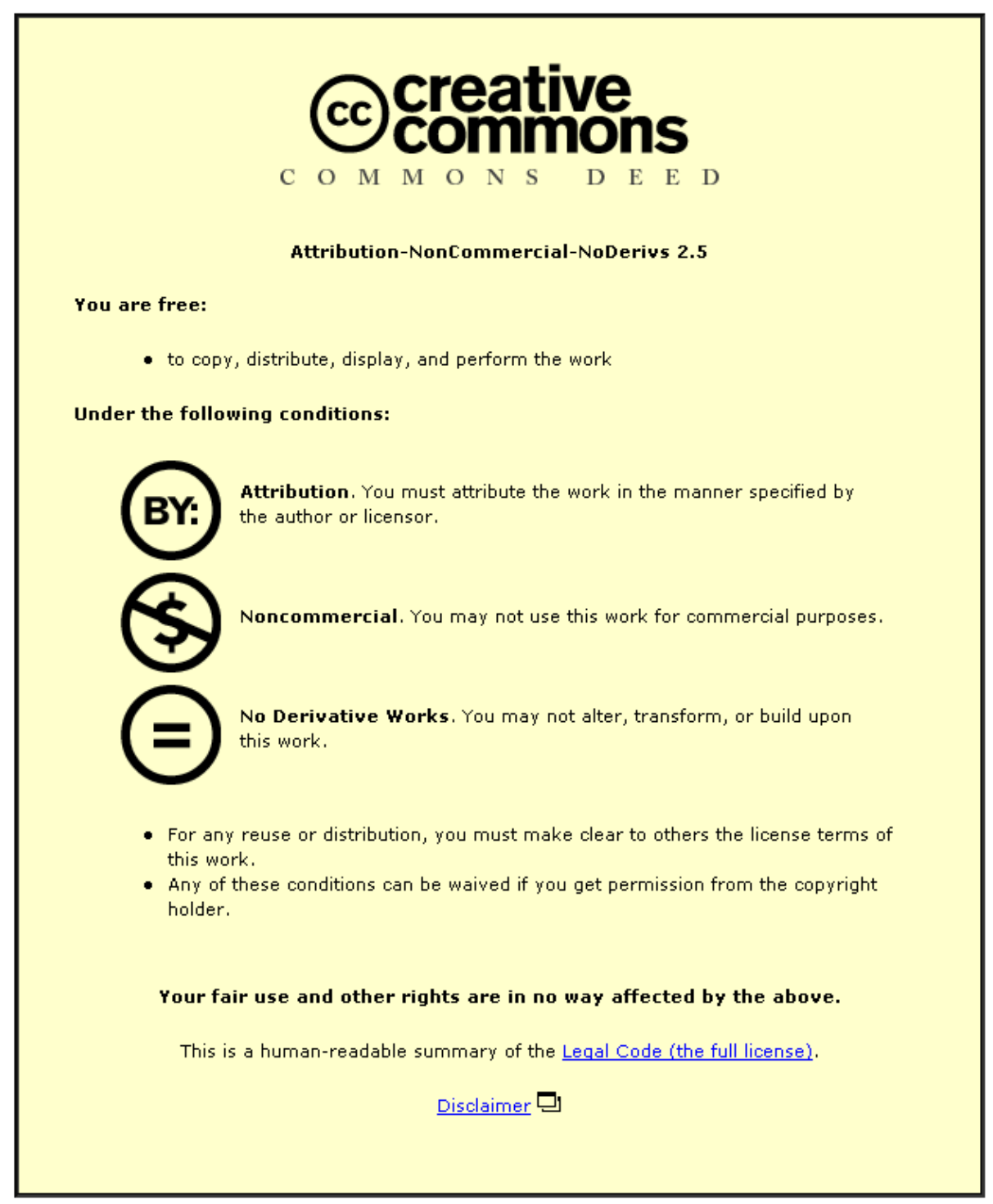

For the full text of this licence, please go to: http://creativecommons.org/licenses/by-nc-nd/2.5/ 


\title{
Systems modelling approaches to the design of safe healthcare delivery: ease of use and usefulness perceived by healthcare workers
}

\author{
Gyuchan Thomas Jun ${ }^{1}$, James Ward ${ }^{2}$ and P. John Clarkson ${ }^{3}$ \\ Department of Engineering, University of Cambridge, UK \\ 1, 2, 3 Engineering Design Centre, Department of Engineering, Trumpington Street, CB2 1PZ, Cambridge, UK \\ ${ }^{1}$ Phone: +44(0)1223 332673, Fax: + 44(0)1223 332662, Email: gj225@cam.ac.uk (corresponding author) \\ ${ }^{2}$ Phone: +44(0)1223 765107, Fax: +44(0)1223 332662, Email: jrw38@cam.ac.uk \\ ${ }^{3}$ Phone: +44(0)1223 748247, Fax: +44(0)1223 332662, Email: pjc10@eng.cam.ac.uk
}

\begin{abstract}
The UK health service, which had been diagnosed to be seriously out of step with good design practice, has been recommended to obtain knowledge of design and risk management practice from other safety-critical industries. While these other industries have benefited from a broad range of systems modelling approaches, healthcare remains a long way behind. In order to investigate the healthcare-specific applicability of systems modelling approaches, this study identified ten distinct methods through meta-model analysis. We then evaluated healthcare workers' perception on 'ease of use' and 'usefulness.'

The characterisation of the systems modelling methods showed that each method had particular capabilities to describe specific aspects of a complex system. However, the healthcare workers found that some of the methods, although potentially very useful, would be difficult to understand, particularly without prior experience. This study provides valuable insights into a better use of the systems modelling methods in healthcare.
\end{abstract}

Keywords: Systems modelling; healthcare; system design; patient safety; risk management.

Statement indicating the relevance of the findings for ergonomics practice

The findings in this study provide insights into how to make a better use of various systems modelling approaches to the design and risk management of healthcare delivery systems, which have been a growing research interest among ergonomists and human factor professionals. 


\section{Introduction}

Healthcare is a highly pressured, complex and diverse system, where the potential for error and accidents is ever present. Ensuring the safety of patients has become one of the most important challenges facing healthcare especially since the publication of a report, "To Err is Human" by the Institute of Medicine (Kohn et al. 2000). In this report, medical errors in hospitals were estimated to be the seventh leading cause of death (44,000 98,000 deaths per year) in the United States, and rank higher than motor vehicle accidents, breast cancer or AIDS (Kohn et al. 2000). In many other countries, including the UK, it was suggested that adverse events, in which harm is caused to patients, occur in around 10\% of admissions (DH 2000).

In response to these problems, healthcare, which had been diagnosed to be seriously out of step with modern systems thinking and good design practice (Clarkson et al. 2004), began to adopt safety approaches from other safety-critical industries, where effective design and risk management are well established (DH 2001, Clarkson et al. 2004, Reid et al. 2005). These industries include the aviation, nuclear power and chemical industries where good systems engineering and human factors practices have been adopted to design a safe system and operate it safely. One aspect of attention to systems design for safety is risk management, which has been widely and successfully applied in many safety critical industries.

Risk management usually begins with defining the scope of a system and describing its intended behaviour. Next, the hazards in the system are identified and their associated risks analysed and prioritised. Finally, new design concepts are generated to eliminate high risk elements. Various techniques for hazard identification and risk analysis have been developed and used to meet different needs for different industries and situations. These techniques include Failure Mode and Effects Analysis (FMEA), Hazard and Operability Studies (HAZOP), Human Error Analysis (HEA) and barrier analysis, just to name a few.

Whatever the choice of risk analysis technique, many other industries noticed that having a clear system understanding is an essential prerequisite for thorough and effective risk analysis (Redmill et al. 1999). 
They have tried to make the most of a broad range of systems modelling methods (methods of diagrammatic description of systems, which in this paper we also call 'diagram types') and utilised ones suitable for their application areas. Some examples are listed below:

- Process flowcharts and block diagrams for analysing hazards throughout the product's life cycle using FMEA (DYADEM 2003);

- Piping \& instrumentation diagrams, process flowcharts, utility flow diagrams and layout drawing for analysing risks in chemical processes using HAZOP (Hyatt 2003);

- Context diagrams and data flow diagrams for identifying hazards in a semi-automated technical system using HAZOP (Redmill et al. 1999);

- Hierarchical task analysis and state space diagrams for identifying errors in the use of consumer products using SHERPA (Stanton and Baber 2005).

Although risk management has gained growing acceptance in a number of clinical areas over the past few years (DeRosier et al. 2002, Lyons et al. 2004, Esmail et al. 2005, Sheridan-Leos et al. 2006, van Tilburg et al. 2006), a very limited range of diagram types - i.e. mostly hierarchical task analysis or flowcharts - has been used. A few other types of diagrams, such as sequence diagrams or swim lane activity diagrams, have been tried in healthcare (Middleton and Roberts 2000, Pradhan et al. 2001, Beuscart-Zephir et al. 2007), but only in isolated situations and without overall consideration of alternative systems modelling methods.

The need has been articulated for better application of systems modelling to healthcare (Clarkson et al. 2004, Edwards 2005), given the diversity and complexity of the healthcare system. Some care processes involve cross-organisational team working with multiple stakeholders along with complex transfers of information, medication and patients, whereas others involve only a few individuals performing relatively simple tasks. Some care processes involve interactions with complex, advanced technology, whereas others involve only human-to-human interactions. The diverse attributes of these care processes, consisting of tasks, technology, information, individuals and teams, contribute to the introduction of patient safety incidents in a variety of ways (Vincent et al. 1998).

In spite of the potential benefits of using systems modelling methods for a better understanding of care processes, no evidence was found of a range of methods being systematically applied in healthcare. We 
believe that a primary reason for the lack of use of systems modelling methods in healthcare is a dearth of knowledge of what methods are available and how they differ from each other. Secondly, and more importantly, healthcare workers might require a particular balance between practicality and utility of systems modelling methods; modelling approaches are unfamiliar to the majority of healthcare workers (Harper and Pitt 2004) and therefore they are less likely to possess the skills necessary to develop models in contrast to the availability of such skills in many other industrial sectors.

Deciding what models to use are often characterised as an art rather than science. It has been widely recognised that deciding what modelling methods best suit 'users' needs' requires the skilful balance of benefits and costs (Chahed et al. 2006, Davis 2008). A degree of experimentation with users has been suggested to be necessary to identify their needs (Davis 2008), but this has not been carried out in the healthcare context.

Thus, the objective of this study is twofold. The first is to explore and characterise various systems modelling methods so that we can identify a broad range of distinct systems modelling methods for healthcare application. The second is to evaluate how healthcare workers perceive 'ease of use' and 'usefulness' of such methods so that we can gain some insight into how to better use available methods in support of risk management in healthcare.

The next section presents the research approach followed for developing a systems modelling method characterisation framework and evaluating each method. This is then followed by a detailed description of the results. The paper then ends with a discussion of the insight gained from the study.

\section{Research approach}

The approaches employed throughout this research draw upon a number of the methodological stages. The first stage comprises an exploratory study about model usage in healthcare and other safety critical industries through a literature review and interviews with healthcare workers. The second stage comprises three case 
studies in which each of three different care scenarios was modelled using different diagram types. The third stage is an evaluation, during which healthcare workers' perception on the 'ease of understanding' and ‘usefulness’ were assessed using interview-based questionnaire. The details of each stage follow.

\subsection{Exploratory stage - literature review and unstructured interviews}

The objective of this stage was to investigate the usage of systems modelling methods in healthcare and other industries. Literature review process was employed to understand the current systems modelling practices reported to be used in healthcare and to explore a variety of systems modelling methods developed and applied in other industries. In addition, one-hour unstructured interviews were carried out with three clinical risk managers and one service improvement manager from Cambridgeshire hospitals and a clinical risk manager from the Cambridgeshire Primary Care Trust to investigate the current usage of systems modelling methods in healthcare. The scope of the review included not only the use of diagram types in conjunction with risk analysis, but also the use of general purpose diagram types from various disciplines, e.g. software engineering, systems engineering, ergonomics, business process modelling, operations management, etc.

Multiple literature search strategies were employed to explore across a number of disciplinary boundaries. This included searching electronic databases (PubMed, Web of Knowledge), grey literature, multiple websites (Google / Google Scholar) and published books from a range of disciplines and sectors. The initial search of the above corpus was driven by combinations of keywords, including all variants of different spellings, grammatical forms and synonyms: for example (Modelling OR Modeling OR Mapping) AND (System OR Process). Other key words, such as (Healthcare OR Health Care) and Safety, were optionally used to narrow down the results. A great number of journal articles on mathematical modelling were excluded since conceptual models, i.e. diagrammatic representations, were the prime concern of this study. The reference trails from the initially-identified materials were also followed. 
One of the challenges of this review was in dealing with so many variations and extensions of modelling methods. For example, the Yourdon Structured Method (YSM), one of the software engineering modelling methods, had moved progressively through four different versions over 15 years since its launch 1981 (Topper et al. 1994). The first version of the Yourdon technique was based on function-based modelling. This was followed by event-based models and state-based models and the current version includes objectoriented models. Moreover, a great number of domain-specific variations from such primary progression have been developed.

In order to overcome these challenges it was decided to keep the literature search focusing on 'primary’ and 'general-purpose’ modelling methods rather than domain-specifically developed modelling variations. For example, whilst journals tended to describe a great number of methods adapted for specific purposes and domains, published books were more helpful in getting an overall view on primary methods.

\subsection{Prescriptive stage - case studies}

\subsubsection{Method characterisation framework development - Meta model analysis}

In order to identify limited but distinctive modelling methods for healthcare application, the systems modelling methods reviewed from the literature were characterised and categorised using meta-models, i.e. a model of the model, which refer to: modelling elements (nodes and links); how they are constructed; and how they relate to one another. This study extended the meta-model analysis, which Holt (2004) used to compare different diagram types of the Unified Modeling Language (UML), to a broader range of modelling methods including Structured Analysis and Design (SA/SD) and Integrated Definitions (IDEF) methods. Accordingly, a method characterisation framework was developed to describe ten different diagram types and compare them in a clear and structured manner. 


\subsubsection{Method application to healthcare - Case studies}

A case study approach was chosen to develop detailed and intensive knowledge about systems modelling applications in the context of a small number of healthcare scenarios. Three case studies were chosen from the authors' network of contacts. We attempted to find care processes which had system-level interactions between different departments, since transfer of care (inter- or intra-facility transfer of patients) is more likely to pose potential risks for patient safety (Forster et al. 2003, Harrison et al. 2005) and be more worthy of study. However, more importantly, case studies had to be of interest to healthcare practitioners if they were to engage with them. Under these limitations, the following three cases were selected:

Case Study 1: A patient discharge process from a medical ward; Case Study 2: A diabetic patient care process in a GP practice; Case Study 3: A prostate cancer diagnosis process in a hospital.

Case Study 1 covers both intra- and inter-facility transfers (between a pharmacy, a ward and patient's home). Case Study 2 covers inter-facility transfer (between a GP surgery and a hospital). Case Study 3 consists of intra-facility transfer (between a clinical department and a ward).

In all cases, process information collection and modelling were carried out iteratively. Information was gathered about how the care process works, primarily through the interviews with key healthcare workers, and complementarily using informal observation and documentary analysis. The interviews for each case study consisted mostly of three to four one-hour sessions with different interviewees or multiple sessions with the same interviewees. Generally, after the first interview, it was possible to draft basic system models. These models were used as inputs to the following interviews, and were verified and completed step-by-step through iterative information collection and modelling cycles. The semantic consistency between different diagram types was repeatedly maintained and checked by the interviewees.

Before or during the interviews, national or local policy documents were identified and collected. These documents assisted the learning of new terminology and the building of high-level general system models. For Case Study 1 only, observations were additionally carried out by attending two multidisciplinary 
team meetings and shadowing two pharmacists on their ward-rounds. The observations helped to give a direct and detailed understanding of the specific individual activities. This approach, though valuable, was not feasible for all three case studies owing to the research sites' different commitments to and positions on patients’ privacy. Both Microsoft Visio and Adobe Illustrator were used as diagramming tools.

The case studies took place in Cambridge, UK with approval from the Cambridge Local Research Ethics Committee.

\subsection{Evaluation stage - interview-based questionnaire}

After generating three sets of ten system models, healthcare workers' perceived 'ease of use' and 'usefulness' of their models were evaluated through the following criteria and procedure.

\subsubsection{Evaluation criteria}

This study had the challenges involved in accessing healthcare workers, which meant that the evaluation of ten different conditions (ten different types of diagrams) often had to be done within one hour. Based on the Technology Acceptance Model (Davis 1989), we evaluate their perceived ‘ease of use’ and ‘usefulness’ by scale-based questionnaire and open-ended feedback.

This approach, which represents the most widely applied model of user acceptance and usage of information technologies, suggests that two specific beliefs - perceived 'ease of use' and perceived 'usefulness' - determine one’s behavioural intention to use a technology, in this study modelling method acceptance by healthcare workers.

\subsubsection{Questionnaire building}

The following five statements were generated to evaluate the 'ease of use' and 'usefulness' of each diagram.

I. This diagram is easily understandable.

II. This diagram is helpful in better understanding and communicating how the system works.

III. This diagram is helpful in identifying and analysing task-related hazards.

IV. This diagram is helpful in identifying and analysing human resource-related hazards.

V. This diagram is helpful in identifying and analysing information/material-related hazards. 
'Ease of understanding', which is a fundamental attribute of 'ease of use' for conceptual models, was captured in Statement I. 'Usefulness' was measured by different types of 'usefulness', capturing not only general 'usefulness' for system understanding and communication (Statement II), but also more specific 'usefulness' for identifying and analysing specific hazard types, such as task, human resource and information/material (Statement III, IV and V). The participants were asked to indicate their (dis)agreement with each statement on a five-point scale (strongly disagree; disagree; neither agree nor disagree; agree; strongly agree).

In Statements III, IV and V, the three types of hazards were defined in consideration of safety-related issues in healthcare. In general, the majority of healthcare activities are based on human tasks, which are the main concern of most human error analysis methods. On the other hand, system-level issues relating to information and human resources are also of great concern to healthcare, e.g. wrong/delayed information transfer and unclear responsibilities (Wilson et al. 2005, Riley et al. 2006, Glintborg et al. 2007). The importance of these system-level issues was also found in this study during the interviews with healthcare managers. A senior manager in a local hospital emphasised the existence of potential hazards in the provision of human resources in the following comment.

Human resource is the biggest problem we face at the moment. If key persons are off sick, a whole process seems to be founded on a key individual. You can not dictate it or control it. The NHS does not have resilience or redundancy built into human resource to cover every single key task.

A risk manager in another local hospital commented on potential hazards of information transfer.

We had communication problems all the time. It was a breakdown in communication that causes the whole process to go wrong. However, we could not see how it went wrong.

\subsubsection{Recruiting participants}

In total, 29 participants were recruited for the diagram evaluation: seven clinical staff (2 general practitioners, 2 nurses, 2 pharmacists and 1 occupational therapist), fifteen healthcare managers (8 service improvement managers, 2 risk managers, 2 discharge managers and 2 general mangers) and seven healthcare researchers (2 psychologists, 2 pharmacists, 2 engineers and 1 ergonomist). Seventeen responses were obtained from Case Study 1 and six responses were gained from each of the other two case studies. All participants answered 
Statement I, but one participant was not able to finish answering Statement II owing to an unscheduled patient visit. Eighteen participants answered Statements III V, since these statements were included part way through the study.

\subsubsection{Evaluation procedure}

Evaluation sessions took one and half hours on average and a maximum of two and half hours (depending on the participants' willingness to stay on). At the beginning of each evaluation session, each diagram was presented and explained to the participant for 15 20 minutes.

At the beginning of the questionnaire, each participant was asked to fill in background information such as their job type, period of time working in healthcare and previous experience with the diagrams (in terms of whether they had used and/or generated such diagrams). In Case Study 1, which partially acted as a pilot study, the questionnaire was carried out in two different ways: self-completion and interview. We learned that the interview-based questionnaire was very effective in capturing rich qualitative feedback, so this approach was used throughout Case Studies 2 and 3. The participants' qualitative feedback on each diagram, i.e. why do you (dis)agree with the statements, was audio-recorded.

\subsubsection{Analysis}

First, a (3×10) mixed ANOVA (case study×diagram types) was used to investigate the effect of the case study on the response patterns; where the five levels of agreement (from strongly disagree to strongly agree) were represented by five response scales (one to five). Across the three case studies, the percentage agreement with each of the five statements - i.e. how many percent of the participants agreed to the statements - was analysed to investigate the overall response patterns, followed by the analysis of the qualitative feedback to interpret the rationale behind the patterns. In addition, the participants’ prior experience with the five groups of diagram types (similar diagram types were grouped together for convenience and will be further explained in 
Table 3) was initially analysed to investigate the participants' diagram experience profile referenced to their job types.

\section{Results}

\subsection{Systems modelling methods in healthcare and other industries}

The literature review showed that healthcare has heavily relied on flowcharts (DeRosier et al. 2002, Esmail et al. 2005, Sheridan-Leos et al. 2006, NHS Institute for Innovation and Improvement 2007)with limited understanding of various alternative systems modelling methods. The findings from the interviews with the four clinical risk managers showed that the use of systems modelling methods for risk management was even more limited. Their risk management efforts mainly focused on analysing adverse incidents reactively rather than doing proactive risk assessment. The interview with the service improvement manager rather showed that flowcharts have been dominantly used for general service quality improvement.

Conversely, other safety-critical industries have proactively managed risk and extensively applied diverse modelling methods developed for use by various disciplines. For example, human factors specialists have used a large set of task-analysis methods with a special interest in understanding interactions between physical devices and individual behaviour. These methods include input-output diagrams, process charts, functional flow diagrams, information flow charts, etc (Kirwan and Ainsworth 1992). In the field of management science, many process models have been developed to improve business processes on their own or in conjunction with simulation techniques. These methods include process maps, activity cycle diagrams, stock flow diagrams, etc (Pidd 2003, Bozarth and Handfield 2005).

Since the 1970s, software and systems engineers have developed many types of modelling languages to design and analyse complex systems. These languages, which consist of several different individual diagram types, include Structured Analysis and Design (SA/SD), Integrated Definitions (IDEF) and the Object-Oriented Method (OOM). Recently collective efforts have been made to unify diverse modelling 
methods and produced the Unified Modeling Language (UML) for software engineering (OMG 2009) and the Systems Modeling Language (SysML) for broader domains including hardware, software, information, processes, personnel and facilities (OMG 2008).

Many researchers, meanwhile, have tried to categorise a broad range of modelling methods using various criteria: data, function, network, people, time and motivation (Zachman 1987); vision, process, structure and behaviour (Eriksson and Penker 2000); organisation, data, control, function and product/service (Davis 2008). Although these categorisations are helpful in roughly grouping various diagram types, they are too broad or general to be readily helpful for healthcare workers to tell the difference between modelling methods. In order to assist healthcare workers understand more specific distinctions between modelling methods and recognise the need for them (beyond flowcharts), this study developed a characterisation framework of systems modelling methods, which is presented in the next section.

\subsection{Development of a characterisation framework of systems modelling methods}

Analysing various modelling methods used across the disciplines, we found two things. First, the majority of modelling methods used in different disciplines differ essentially only in their names, representing identical aspects of a system with only some minor variations, e.g. different shape of boxes or arrows, etc. Second, the modelling languages developed in software and systems engineering cover most of the modelling methods used in other disciplines. Therefore we decided to develop a characterisation framework based on the modelling languages developed in software and systems engineering.

The meta-model analysis was carried out to investigate what the nodes and links of such modelling methods primarily represent. Three different primary types of nodes (boxes or circles) and links (connecting lines between nodes) were identified as shown in Figure 1: activities, stakeholders and information/material for nodes, and hierarchy, sequence and information for links. Each diagram type utilises these nodes and links in different ways to represent different aspects of a system. 


\section{INSERT FIGURE 1 AROUND HERE}

As a result of the meta-model analysis, we identified ten diagram types with distinctive features in terms of their nodes and links and their main functions as summarised in Table 1 . The first three diagram types (1)stakeholder diagrams, (2)information diagrams and (3)process content diagrams) show hierarchical links between stakeholders, information and activities, respectively. The second three diagram types (4)flowcharts, (5)swim lane activity diagrams and (6)state transition diagrams) address some limitations of the static nature of the hierarchical-link diagrams by showing sequential links of activities or states. The last four diagram types describe information inputs and outputs between stakeholders ( 7 communication diagrams, (8) sequence diagrams) and activities (9data flow diagrams and (10IDEF0).

\section{INSERT TABLE 1 AROUND HERE}

In order to show healthcare workers primary differences of these ten diagram types in a clear manner, we have developed a framework with three axes (activity, stakeholder and information views) and three concentric circles (hierarchical, sequential and information links) and mapped each of the ten diagrams onto it as shown in Figure 2.

\section{INSERT FIGURE 2 AROUND HERE}

The diagram types positioned on one axis explicitly represent a single modelling view with the other two views absent or implicit, whereas the diagram types positioned between two axes explicitly represent the two views at the same time. For example, (4)flowcharts, (5)state transition diagrams and (1)process content diagrams are all located on the activity axis; these diagrams explicitly represent only activity. On the other hand, data flow diagrams and IDEF0, which are located between the activity and information axes, explicitly represent both activity and information at the same time. 


\subsection{Systems models of a prostate cancer diagnosis process}

The ten different diagram types were used to describe each of the three care scenarios. The following figures show ten simplified system models describing, for example, a prostate cancer diagnosis process.

INSERT FIGURE 3 AROUND HERE

INSERT FIGURE 4 AROUND HERE

INSERT FIGURE 5 AROUND HERE

INSERT FIGURE 6 AROUND HERE

INSERT FIGURE 7 AROUND HERE

INSERT FIGURE 8 AROUND HERE

INSERT FIGURE 9 AROUND HERE

INSERT FIGURE 10 AROUND HERE

INSERT FIGURE 11 AROUND HERE

INSERT FIGURE 12 AROUND HERE

\subsection{Evaluation results}

The overall evaluation results across the three case studies were firstly compared using mixed ANOVA to test the effects of the case study on response patterns. The five $(3 \times 10)$ mixed ANOVA (case study $\times$ diagram types) for each statement revealed a non-significant effect of the type of case study on the response patterns (Statement I: $F(2,26)=2.49, p=0.10$, Statement II: $F(2,25)=0.96, p=0.40$, Statement III: $F(2,15)=2.6$, $p=0.11$, Statement IV: $F(2,15)=2.3, p=0.14$, Statement $V: F(2,15)=0.48, p=0.63)$. It meant that the response patterns across the three case studies were sufficiently similar to be collectively analysed.

Table 2 summarises the percentage agreement to each of the five statements - i.e. how many percent of the participants agreed to the statements. The diagram types are marked with three different sizes of circles according to the percentage agreement: big circles for more than 70 percent (inclusive) agreement; small 
circles for less than 50 percent agreement; medium-sized circles for between 50 (inclusive) and 70 percent agreement.

\section{INSERT TABLE 2 AROUND HERE}

In summary, the largest number of the participants agreed that flowcharts were easy to understand and were helpful in understanding care processes and analysing task-related hazards. However, the potential utility of the other diagram types was also identified. The participants' prior experience with different diagram types and detailed findings of the participants' response patterns to each of the five statements now follow.

\subsubsection{Participants' experience with the diagram types and their job types}

The participants' previous experience with the five groups of diagram types, captured at the beginning of the diagram evaluation, is summarised in Table 3. Overall, the second group (either flowcharts or swim lane activity diagrams) had been previously experienced by the largest number of the participants (76\%) whereas state transition diagrams and the four diagram types with information links (7), (8), (9), (1)) had been previously experienced by the least (14 21\%).

\section{INSERT TABLE 3 AROUND HERE}

The participants with different job types had different levels of prior experience with the diagrams. Table 3 also shows that the clinical staff who participated in this study have much less experience with any type of the diagrams than the healthcare managers and researchers. In particular, none of the clinical staff had previous experience with the information-link diagrams (7), (8), (9), (1)).

\subsubsection{Ease of understanding (Statement I)}

In general, the diagrams having hierarchical links (1), (2), (3) and sequential links (4), (5), (6) were rated more ‘easily understandable’ than the diagrams with information links (7), (8), (9), (10). Table 2 shows that approximately 80 percent of the participants responded positively (either agree or strongly agree) to 'the ease 
of understanding' of the diagrams with hierarchical links. Flowcharts, which have been extensively used in healthcare, were rated as 'easily understandable' by the largest number (97 percent) of the participants.

The participants’ prior experience generally influenced their perception of the ease of understanding.

Figure 13 shows the response patterns of two groups: one without any previous experiences with a certain diagram type (black bars) and the other with previous experience (white bars). Generally, a greater percentage of the participants with previous experience with a certain diagram agreed that the diagram was easy to understand than the participants without any experience. The exception was flowcharts; flowcharts were perceived to be easy to understand by a slightly greater percentage of inexperienced participants than experienced.

\section{INSERT FIGURE 13 AROUND HERE}

Many participants, however, mentioned that their preference for flowcharts came from their biased experience with them.

"I tend to be swayed toward the flowcharts because I always use them."

By Healthcare Manager/Service Improvement Manager

"I still tend to use flowcharts. It is the experience that drives me in that direction. I have considerably less experience with any of other methods describing systems."

By Healthcare Researcher/Psychologist

Figure 13 also shows that the gaps of the percentage agreement between the experienced and inexperienced participants varied depending on diagram types, i.e. the participants’ prior experience influenced their perceived 'ease of understanding' of each diagram type to a different degree. Whilst some diagram types (2), (3), (4), (5) had relatively small percentage agreement gaps (5 12\%) between the experienced and inexperienced participants, some other diagram types (๑), (7), (8), (9) had high percentage agreement gaps (43 52\%) between the experienced and inexperienced participants. In the case of state transition diagrams (๑) and data flow diagrams (9), 100\% of the participants with prior experience perceived them as easily understandable whereas only half of the participants without prior experience perceived them as easily understandable. 


\subsubsection{Usefulness - helpful in understanding and communicating how the system works (Statement II)}

In general, the response pattern to Statement II followed the one to Statement I. As Table 2 shows, flowcharts remained the most favoured (89\%) and the diagrams with information links, particularly communication diagrams and sequence diagrams, were again given the lowest percentage agreement for Statement II (39\% and $29 \%$, respectively).

Two distinctive changes from the response pattern of Statement I were found. First, the drop of the percentage agreement (from Statement I to II) for the hierarchical-link diagrams $(\approx 25 \%)$ was relatively greater than for the other diagram types $(\approx 10 \%)$. The participants' comments showed that the hierarchicallink diagrams were generally perceived to be simple enough to be easily understandable, but too simple to be sufficiently informative in understanding how the system works.

The other distinctive change is that state transition diagrams uniquely gained more positive responses (71\% for Statement II and 59\% for Statement I). State transition diagrams were, therefore, perceived as helpful in a general system understanding by the second largest number of the participants in spite of the participants' low (21\%) prior experience.

Many participants commented that state transition diagrams helped them to see care processes in a more patient-focused way. As Figure 8 shows, state transition diagrams can represent patient-related states and corresponding transition actions and conditions.

The participants' following comments on state transition diagrams illustrate the rationale behind their positive responses.

"Quite useful. You picked up a patient in a surgery who you have never seen before, it (state transition diagram) provides a quick summary of what should be done and where they should be and it (state transition diagram) is a more accessible (understandable) format than flowcharts.”

By Clinical Staff/General Practitioner

"I quite like the fact that it (state transition diagram) follows the patient, and what happens to patients. You can have different states of patient and also you can have quite in-depth information underneath what is happening.”

By Healthcare Manager/Service Improvement Manager

"I think this (state transition diagrams) is the best one. It is patient-led and shows clearly what stage a patient is at. State transition diagrams are good for both patients and clinicians.”

By Healthcare Researcher/Pharmacist 


\subsubsection{Usefulness - in view of specific hazard identification and analysis (Statement III, IV, V)}

The general comments from many participants were that some of the diagrams were helpful in systematically identifying hazards - i.e. going through all the elements of a system without missing any out - but the diagrams provided very limited information for estimating risk and consequences. The participants generally mentioned that consequences of hazards were more likely to be estimated from their individual mental models. Nevertheless, different diagram types were perceived as helpful to a different degree in analysing the different types of hazards.

\subsubsection{Identifying and analysing task-related hazards}

Flowcharts were perceived as most favoured (89 percent agreed) for this purpose, and state transition diagrams were the second most favoured (78 percent agreed) as shown in Table 2. The potential of state transition diagrams in estimating consequences of risk was illustrated in the following comment.

"The states in state transition diagrams could be the states of patient harm. Patients have to stay in the previous state, if any task fails.”

$$
\text { By Healthcare Researcher/Engineer }
$$

\subsubsection{Identifying and analysing human resource-related hazards}

Table 2 also shows that swim lane activity diagrams, which represent tasks and responsibilities explicitly, were the most favoured (83 percent agreed) for this purpose; the participant's comment below illustrate it as well. Flowcharts ranked the second (56 percent agreed) although flowcharts did not show responsibilities explicitly.

"What is really important about healthcare is to understand the interactions between different people and responsibilities of different people and it (swim lane activity diagrams) does that.”

By Healthcare Researcher/Psychologist

\subsubsection{Identifying and analysing information/material-related hazards}

Table 2 shows that communication diagrams, which explicitly show information/material interactions among stakeholders, were the most favoured (72 percent agreed) for this purpose and information diagrams ranked the second (67 percent agreed). 


\section{Discussion and conclusions}

\subsection{Systems modelling method characterisation}

The diagram characterisation framework developed in this study showed that each diagram type had its own unique capability of highlighting different, yet limited, aspects of a complex system; no particular diagram explicitly showed all aspects. The characterisation framework effectively helped in comparing the ten different diagram types and showed that they evenly covered the representation of different aspects of a complex system. They are far from being a comprehensive list of all the diagram types, but the framework still provides an effective base for making further comparisons with additional diagram types.

While this study intentionally identified the ten different diagram types with specific and distinct features, there are some other broadly-defined diagram types that represent not all, but multiple types of links and nodes. For example, block definition diagrams in the SysML encompass both hierarchical links and information links. In addition, nodes in block definition diagrams include stakeholders as well as information/material (OMG 2008). Such broad diagram definitions can blur the distinction between diagram types and may lead to information overload to users. It remains an open question as to how much complexity users can accommodate in conceptual models, but it is apparent from the evaluation results in this study that the majority of healthcare users are unlikely to be comfortable with diagrams representing multiple links; the majority of the participants were not comfortable even with the diagrams with only information links.

Conversely, within these ten different diagrams, there are similar types of diagrams in terms of what they primarily represent. They have been included separately since each of them presents information in a distinct way which can be complementary to the other diagrams. For example, although both communication diagrams and sequence diagrams represent information interactions between stakeholders, their different layouts emphasise different aspects of a system; communication diagrams underlines how stakeholders are connected to each other whereas sequence diagrams highlight the sequence of interactions. 


\subsection{Ease of use and usefulness of the systems modelling methods}

The characterisation framework developed in this study enabled the general function of each diagram type to be understood. Further study through the diagram evaluation with potential healthcare users investigated the healthcare-specific applicability of each diagram. The participants’ prior experience with certain diagram types generally influenced how they perceived the 'ease of use' ('ease of understanding' in this study). As the adapted Technology Acceptance Model (TAM) in Figure 14 suggests (Venkatesh 2000), prior to direct experience with a certain specific modelling method, individuals are expected to anchor their perceived 'ease of use' of the new specific modelling method to their general belief regarding modelling methods. Hence, individuals are expected to adjust their method-specific perceived 'ease of use' to reflect their experience of using the method.

\section{INSERT FIGURE 14 AROUND HERE}

This study found, however, that the participants’ prior experience with certain diagrams influenced their perceived 'ease of use' to a different degree towards each diagram. This may suggest that some diagram types can be adopted with less effort by either experienced or inexperienced users, while some other diagram types can be more difficult to adopt, particularly by the healthcare users without prior experience. Hence, in spite of the unique 'usefulness' that particular diagram types might provide, they may be difficult to be adopted by a wide range of healthcare users.

Different professional groups in healthcare, e.g. clinicians, healthcare managers and healthcare researchers, were found to have different levels of previous experience with the diagram types. In particular, a limited awareness of general systems modelling methods was particularly acute in the clinical staff participant group; only 57\% of the clinical staff reported that they had used any kind of systems modelling methods before. This might suggest that there is a need to increase awareness about the benefits of general modelling approaches with clinical staff before providing particular support for using specific methods. 
Overall, the response pattern to the perceived 'usefulness' followed that of the perceived 'ease of understanding'. The Technology Acceptance Model in Figure 14 also posits that perceived 'usefulness' will be influenced by perceived 'ease of use'. The participants in this study, though, commented more specifically that each of the ten different diagram types has its own specific 'usefulness' for understanding different aspects of a system. Table 4 summarises the applicability of each modelling method based on the participants’ responses. For example, state transition diagrams along with flowcharts can be highly applicable to representing patient journeys. State transition diagrams, in particular, were found in this study to provide very quick, accessible, patient-led views, which have been known to be crucial for good quality care (Kizer 2002, Smith 2006). Process content diagrams, which can facilitate very detailed descriptions of tasks, can be highly applicable to representing individual tasks. When it comes to representing roles and responsibilities, or communication, it was apparent from meta-model analysis that swim lane activity diagrams are highly applicable to representing collaboration, and communication and sequence diagrams to representing communication. Data flow diagrams, which facilitate descriptions of data flow, storage and processing, would be highly applicable to representing human-technology interactions as Redmill applied (1999). IDEF0, which explicitly describes inputs and outputs of activities, can be highly applicable to describing supply chains like medication flows.

\section{INSERT TABLE 4 AROUND HERE}

In conclusion, it is apparent that better use of systems modelling methods may offer great benefits to healthcare, when considering the different advantages each method can offer and the complexity and diversity of the healthcare systems. However, the different modelling experience levels of healthcare workers suggest that different levels of modelling support might be required for different professions. In the case of clinical staff, who has relatively limited modelling experience, increased awareness of modelling methods might be more important. For the healthcare managers and researchers, where more than $80 \%$ have used one or more of 
the systems modelling methods, might benefit more from experiencing a wide range of diagram types.

Technical difficulties might be encountered in assisting healthcare managers and researchers to make healthcare-specific applications of a wide range of diagram types, e.g. how to define a patient's states for state transition diagrams. Clear guidelines or computer-support for healthcare-specific diagramming could reduce barriers in generating and understanding such diagram types.

Although more research is needed to empirically examine the 'ease of use' and 'usefulness' in wider healthcare contexts with a large number of users, this study provided valuable insights into how healthcare can make a better use of systems modelling approaches in support of the design of safe healthcare delivery.

\section{Acknowledgements}

We wish to thank all of those who participated in this study from Cambridge University Hospitals NHS Foundation Trust, Hinchingbrooke Health Care NHS Trust, and the Firs House Surgery in Cambridge, UK. We also acknowledge the support of the Cambridge Local Research Ethics Committee through this study and give special thanks to Dr Zoë Morris for her contribution to discussion. 


\section{References}

Beuscart-Zephir, M.-C., Pelayo, S., Anceaux, F., Maxwell, D. and Guerlinger, S., 2007, Cognitive analysis of physicians and nurses cooperation in the medication ordering and administration process. International Journal of Medical Informatics, 76(Suppl 1), S65-S77.

Blessing, L., Chakrabarti, A. and Wallace, K., 1995, A design research methodology. 13th International Conference on Engineering Design, Glasgow, UK, 502-507.

Bozarth, C. C. and Handfield, R. B., 2005, Introduction to operations and supply chain management, Upper Saddle River, NJ: Pearson Prentice Hall.

Chahed, S., Matta, A., Sahin, E. and Dallery, Y., 2006, Operations management related activities for home health care providers. Information control problems in manufacturing, St Etienne, France, IFAC, 621626.

Clarkson, P. J., Buckle, P., Coleman, R., Stubbs, D., Ward, J., Jarrett, J., Lane, R. and Bound, J., 2004, Design for patient safety: a review of the effectiveness of design in the UK health service. Journal of Engineering Design, 15(2), 123-140.

Davis, F. D., 1989, Perceived Usefulness, Perceived Ease of Use, and User Acceptance of Information Technology. MIS Quarterly, 13(3), 319-340.

Davis, R., 2008, ARIS design platform: advanced process modelling and administration, London: Springer.

DeRosier, J., Stalhandske, E., Bagian, J. P. and Nudell, T., 2002, Using health care Failure Mode and Effect Analysis. The Joint Commission journal on quality improvement, 28(5), 248-267.

DH, 2000, An organisation with a memory: report of an expert group on learning from adverse events in the NHS. London: Department of Health.

DH, 2001, Building a safer NHS for patients: implementing an organisation with a memory. London: Department of Health.

DYADEM, 2003, Guidelines for Failure Modes \& Effects Analysis for medical device, London: CRC press.

Edwards, N., 2005, Can quality improvement be used to change the wider healthcare system? Quality and Safety in Health Care, 14(2), 75.

Eriksson, H. and Penker, M., 2000, Business modeling with UML: business patterns at work, New York: John Wiley \& Sons.

Esmail, R., Cummings, C., Dersch, D., Duchscherer, G., Glowa, J., Liggett, G. and Hulme, T., 2005, Using Healthcare Failure Mode and Effect Analysis tool to review the process of ordering and administrating potassium chloride and potassium phosphate. Healthcare Quarterly, 8(Special issue), 73-80.

Forster, A. J., Murff, H. J., Peterson, J. F., Gandhi, T. K. and Bates, D. W., 2003, The incidence and severity of adverse events affecting patients after discharge from the hospital. Annals of Internal Medicine, 138(3), 161-167.

Glintborg, B., Andersen, S. E. and Dalhoff, K., 2007, Insufficient communication about medication use at the interface between hospital and primary care. Quality and Safety in Health Care, 16(1), 34-9.

Harper, P. and Pitt, M., 2004, On the challenges of healthcare modelling and a proposed project life cycle for successful implementation. Journal of operational research society, 55(6), 657-661.

Harrison, M., Eardley, W. and McCarron, B., 2005, Time to hand over our old way of working. Hospital Medicine, 66(7), 399-400.

Holt, J., 2004, UML for Systems Engineering: Watching the Wheels, London: Institution of Electrical Engineers.

Hyatt, N., 2003, Guidelines for process hazards analysis: hazards identification \& risk analysis, Ontario: CRC Press. 
Jun, G. T., Ward, J. and Clarkson, P. J., 2009, Health care process modelling: which method when? International Journal for Quality in Health Care, 21(3), 214-224.

Kirwan, B. and Ainsworth, L. K., 1992, A guide to task analysis, London: Taylor \& Francis.

Kizer, K. W., 2002, Patient centred care: essential but probably not sufficient. Quality and Safety in Health Care, 11(2), 117-8.

Kohn, L. T., Corrigan, J. M. and Donaldson, M. S. (eds.), 2000, To err is human: building a safer health system, Washington, D.C.: National Academy Press.

Lyons, M., Adams, S., Woloshynowych, M. and Vincent, C., 2004, Human reliability analysis in healthcare: A review of techniques. International Journal of Risk \& Safety in Medicine, 16(4), 223-237.

Middleton, S. and Roberts, A., 2000, Integrated care pathways: a practical approach to implementation, Oxford: Butterworth-Heinemann.

NHS Institute for Innovation and Improvement, 2007, Improvement leaders' guide: process mapping, analysis and redesign.

OMG, 2008, OMG Systems Modeling Language [Online]. Object Management Group, Inc. Available from: http://www.sysmlforum.com/docs/specs/OMGSysML-v1.1-08-11-01.pdf [Accessed July 2009].

OMG, 2009, OMG United Modeling Language, Infrastructure [Online]. Object Management Group, Inc. Available from: http://www.omg.org/docs/formal/09-02-04.pdf [Accessed July 2009].

Pidd, M., 2003, Tools for thinking: modelling in management science, Chichester: John Wiley \& Sons.

Pradhan, M., Edmonds, M. and Runciman, W., 2001, Quality in Healthcare: process. Best practice \& research. Clinical anaesthesiology, 15(4), 555-571.

Redmill, F., Chudleigh, M. and Catmur, J., 1999, System Safety: HAZOP and Software HAZOP, Chichester: John Wiley \& Sons Ltd.

Reid, P. P., Compton, W. D., Grossman, J. H. and Fanjiang, G. (eds.), 2005, Building a better delivery system: a new engineering/health care partnership, Washington DC: National Academies Press.

Riley, R., Manias, E. and Polglase, A., 2006, Governing the surgical count through communication interactions: implications for patient safety. Quality and Safety in Health Care, 15(5), 369-74.

Sheridan-Leos, N., Schulmeister, L. and Hartranft, S., 2006, Failure mode and effect analysis: a technique to prevent chemotherapy errors. Clinical Journal of Oncology Nursing, 10(3), 393-8.

Smith, T., 2006, Changing relationships between people and providers: making sense of patient centred health care. Quality and Safety in Health Care, 15(1), 71-73.

Stanton, N. A. and Baber, C., 2005, Validating task analysis for error identification: reliability and validity of a human error prediction technique. Ergonomics, 48(9), 1097-1113.

Topper, A., Ouellette, D. and Jorgensen, P., 1994, Structured methods: merging models, techniques, and CASE, New York ; London: McGraw-Hill.

van Tilburg, C. M., Leistikow, I. P., Rademaker, C. M., Bierings, M. B. and van Dijk, A. T., 2006, Health Care Failure Mode and Effect Analysis: a useful proactive risk analysis in a pediatric oncology ward. Quality and Safety in Health Care, 15(1), 58-63.

Venkatesh, V., 2000, Determinants of perceived ease of use: Integrating control, intrinsic motivation, and emotion into the technology acceptance model. Information Systems Research, 11(4), 342-365.

Vincent, C., Taylor-Adams, S. and Stanhope, N., 1998, Framework for analysing risk and safety in clinical medicine. BMJ, 316, 1154-1157.

Wilson, K. A., Burke, C. S., Priest, H. A. and Salas, E., 2005, Promoting health care safety through training high reliability teams. Quality and Safety in Health Care, 14(4), 303-9.

Zachman, J., 1987, A framework for information systems architecture. IBM Systems Journal, 26(3), 276-92. 
Table 1. Node-link based diagram characterisation and simple examples (extended from (Jun et al. 2009)).

\begin{tabular}{|c|c|c|c|}
\hline Diagram type & Nodes & Links & Main functions \\
\hline $\begin{array}{l}\text { (1) Stakeholder } \\
\text { diagrams }\end{array}$ & Stakeholder & $\begin{array}{l}\text { Hierarchy } \\
\phi \text { consists of } \\
\Delta \text { has types of }\end{array}$ & $\begin{array}{c}\text { Hierarchically structure of } \\
\text { stakeholders }\end{array}$ \\
\hline $\begin{array}{l}\text { (2) Information } \\
\text { diagrams }\end{array}$ & \begin{tabular}{|c|}
$\begin{array}{l}\text { Information } \\
\text { (document) }\end{array}$ \\
content \\
\end{tabular} & $\begin{array}{l}\text { Hierarchy } \\
\phi \text { consists of } \\
\Delta \text { has types of }\end{array}$ & $\begin{array}{l}\text { Hierarchical structure of } \\
\text { documents or information }\end{array}$ \\
\hline $\begin{array}{l}\text { (3) Process content } \\
\text { diagrams }\end{array}$ & Activity & $\begin{array}{l}\text { Hierarchy } \\
\hat{P} \text { consists of } \\
\Delta \text { has types of }\end{array}$ & $\begin{array}{c}\text { Hierarchical list of } \\
\text { activities }\end{array}$ \\
\hline (4) Flowcharts & $\begin{array}{l}\text { Start/end } \\
\widehat{\text { Decision }} \\
\text { Activity } \\
\end{array}$ & $\begin{array}{c}\text { Sequence } \\
\downarrow\end{array}$ & $\begin{array}{l}\text { Sequential order of } \\
\text { activities }\end{array}$ \\
\hline $\begin{array}{l}\text { (5) Swim lane } \\
\text { activity diagrams }\end{array}$ & \begin{tabular}{|c|} 
Stakeholder \\
Start/end \\
Decision \\
Activity \\
\end{tabular} & Sequence & $\begin{array}{c}\text { Sequential order of } \\
\text { activities with a clear role } \\
\text { definition }\end{array}$ \\
\hline $\begin{array}{l}\text { (6) State transition } \\
\text { diagrams }\end{array}$ & State & $\begin{array}{l}\text { Sequence } \\
\downarrow^{\frac{\text { condition }}{\text { action }}}\end{array}$ & $\begin{array}{c}\text { Change of a system state } \\
\text { over time }\end{array}$ \\
\hline $\begin{array}{l}\text { (7) Communication } \\
\text { diagrams }\end{array}$ & Stakeholder & $\begin{array}{l}\text { Information } \\
\text { /material }\end{array}$ & $\begin{array}{l}\text { Information/material } \\
\text { interactions between } \\
\text { stakeholders }\end{array}$ \\
\hline $\begin{array}{l}\text { (8) Sequence } \\
\text { diagrams }\end{array}$ & Stakeholder & $\stackrel{\text { Information }}{\text { /material }} \longrightarrow$ & $\begin{array}{c}\text { Order of } \\
\text { information/material } \\
\text { interactions between } \\
\text { stakeholders }\end{array}$ \\
\hline $\begin{array}{l}\text { (9) Data flow } \\
\text { diagrams }\end{array}$ & $\begin{array}{c}\text { Data } \\
\text { storage } \\
\end{array}$ & $\stackrel{\substack{\text { Information } \\
\text { /material }}}{\longrightarrow}$ & $\begin{array}{c}\text { Information-processing } \\
\text { activities and information } \\
\text { storage }\end{array}$ \\
\hline (10) IDEF0 & Activity & $\begin{array}{l}\text { Input/output } \rightarrow \\
\text { control } \downarrow \\
\text { resource } \uparrow\end{array}$ & $\begin{array}{l}\text { Information/material inputs } \\
\text { and outputs between } \\
\text { activities and related } \\
\text { resources and controls }\end{array}$ \\
\hline
\end{tabular}


Table 2. Percentage agreement for each statement (extended from (Jun et al. 2009)).

๑: agreement $\geq 70 \%, \bullet: 70 \%>$ agreement $\geq 50 \%$. $\bullet$ agreement $<50 \%$

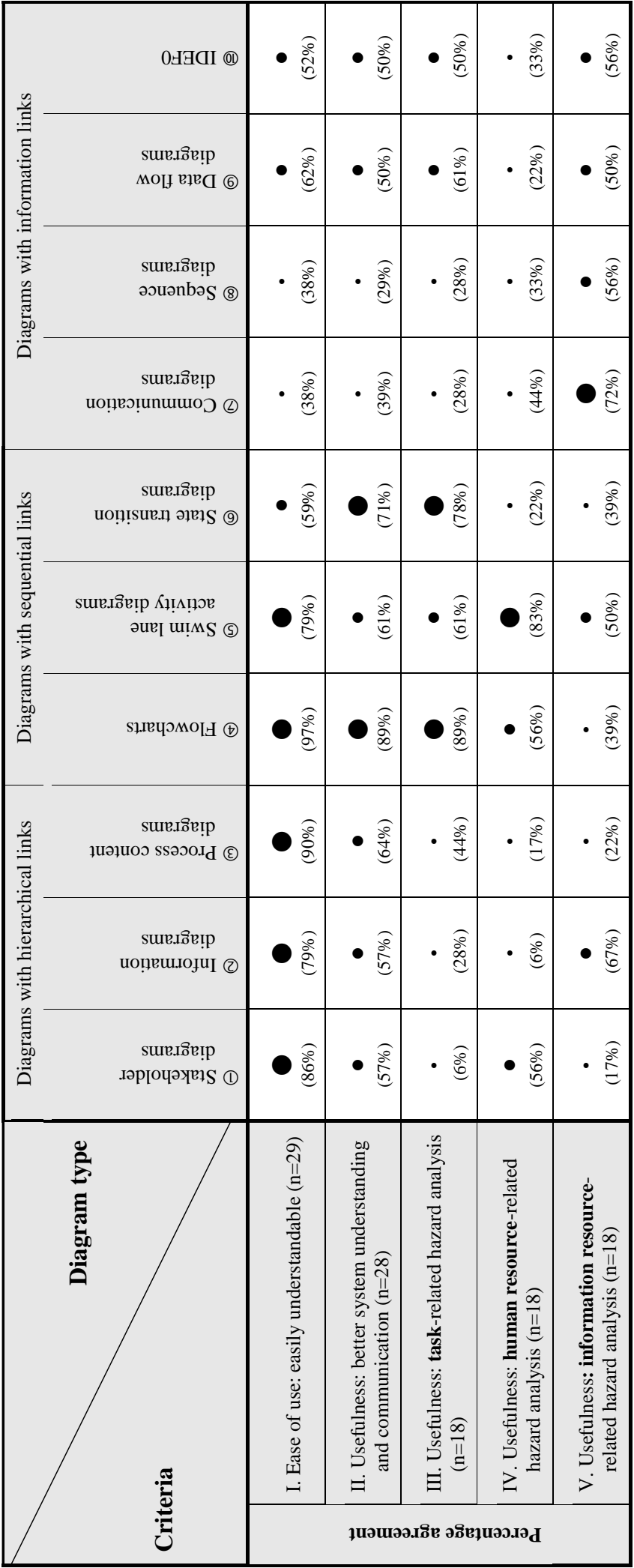


Table 3. Percentage of participants experienced with the five groups of diagrams and their job types.

\begin{tabular}{|c|c|c|c|c|c|c|}
\hline Diagram type & 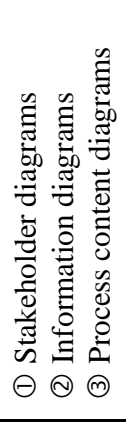 & 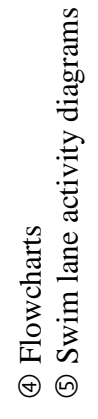 & 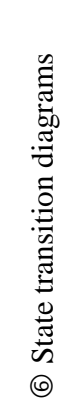 & 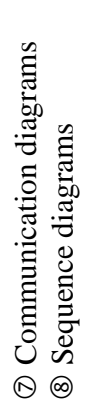 & 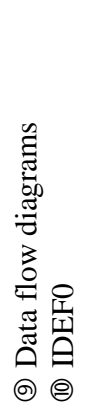 & 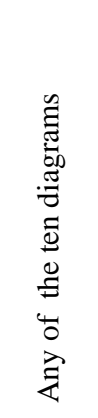 \\
\hline Clinical staff $(\mathrm{n}=7)$ & $\begin{array}{c}\cdot \\
(29 \%) \\
\end{array}$ & $\stackrel{\bullet}{\bullet}$ & $\begin{array}{c}\bullet \\
(14 \%) \\
\end{array}$ & $\stackrel{\bullet}{(0 \%)}$ & $\stackrel{\bullet}{(0 \%)}$ & $\stackrel{\bullet}{\bullet}$ \\
\hline $\begin{array}{c}\text { Healthcare } \\
\text { managers }(\mathrm{n}=15) \\
\end{array}$ & $\stackrel{\bullet}{\bullet}$ & $\underset{(73 \%)}{0}$ & • & $\dot{(20 \%)}$ & $\begin{array}{c}\cdot \\
(33 \%) \\
\end{array}$ & $\underset{(80 \%)}{0}$ \\
\hline $\begin{array}{c}\text { Healthcare } \\
\text { researchers }(\mathrm{n}=7)\end{array}$ & (71\%) & $(100 \%)$ & $\begin{array}{c}\bullet \\
(29 \%)\end{array}$ & $\stackrel{\bullet}{(14 \%)}$ & $\begin{array}{l}\cdot \dot{(14 \%)} \\
\end{array}$ & $(100 \%)$ \\
\hline Overall (n=29) & $\stackrel{\bullet}{\bullet}$ & $\underset{(76 \%)}{\overbrace{(76}}$ & $\begin{array}{c}\cdot \\
(21 \%)\end{array}$ & $\stackrel{\bullet}{(14 \%)}$ & $\begin{array}{c}\cdot \\
(21 \%)\end{array}$ & $\underset{(79 \%)}{\longrightarrow}$ \\
\hline
\end{tabular}


Table 4. Applicability of the different diagram types ( $\bullet$ : applicable, $\bullet$ : highly applicable)

\begin{tabular}{|c|c|c|c|c|c|c|c|c|c|c|}
\hline System aspects of interest & 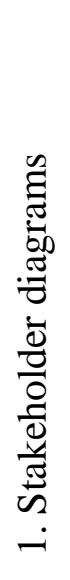 & 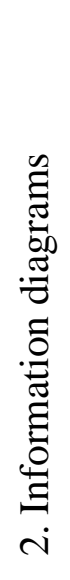 & 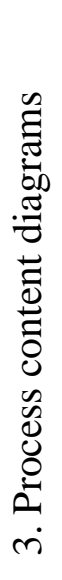 & 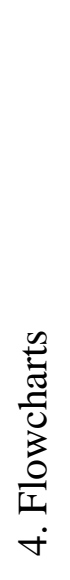 & 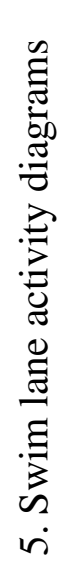 & 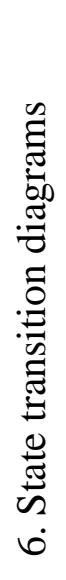 & 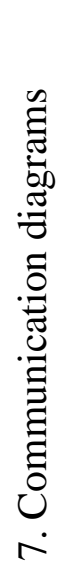 & 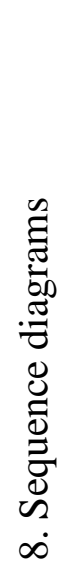 & 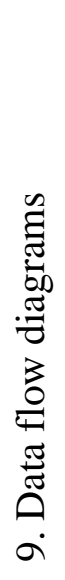 & 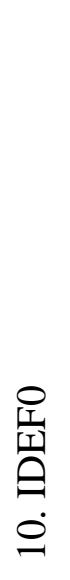 \\
\hline $\begin{array}{l}\text { Process and procedure } \\
\text { e.g. patient journey }\end{array}$ & & & $\bullet$ & 0 & & 0 & & & & - \\
\hline $\begin{array}{l}\text { Individual tasks } \\
\text { e.g. self-medication }\end{array}$ & & & O & - & & & & & & \\
\hline $\begin{array}{l}\text { Roles and responsibilities } \\
\text { e.g. multi disciplinary team }\end{array}$ & $\bullet$ & & & & - & & - & & & \\
\hline $\begin{array}{l}\text { Communication } \\
\text { e.g. referral flows }\end{array}$ & & $\bullet$ & & & & & - & - & 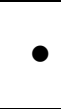 & - \\
\hline $\begin{array}{l}\text { Human-technology interface } \\
\text { e.g. use of medical devices }\end{array}$ & & & • & & & & - & • & 0 & \\
\hline $\begin{array}{l}\text { Procurement and supply } \\
\text { e.g. medication flows }\end{array}$ & & & & 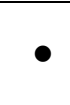 & & & 0 & - & - & ○ \\
\hline
\end{tabular}




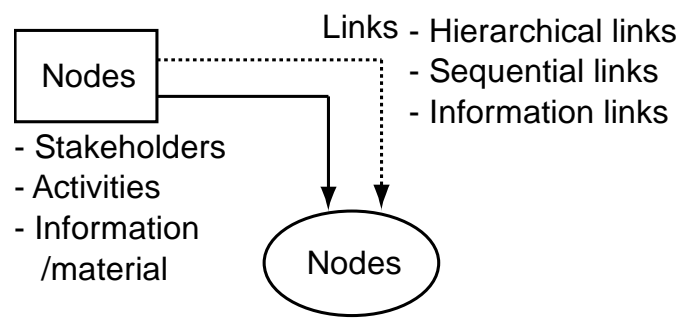

Figure 1. What nodes and links represent

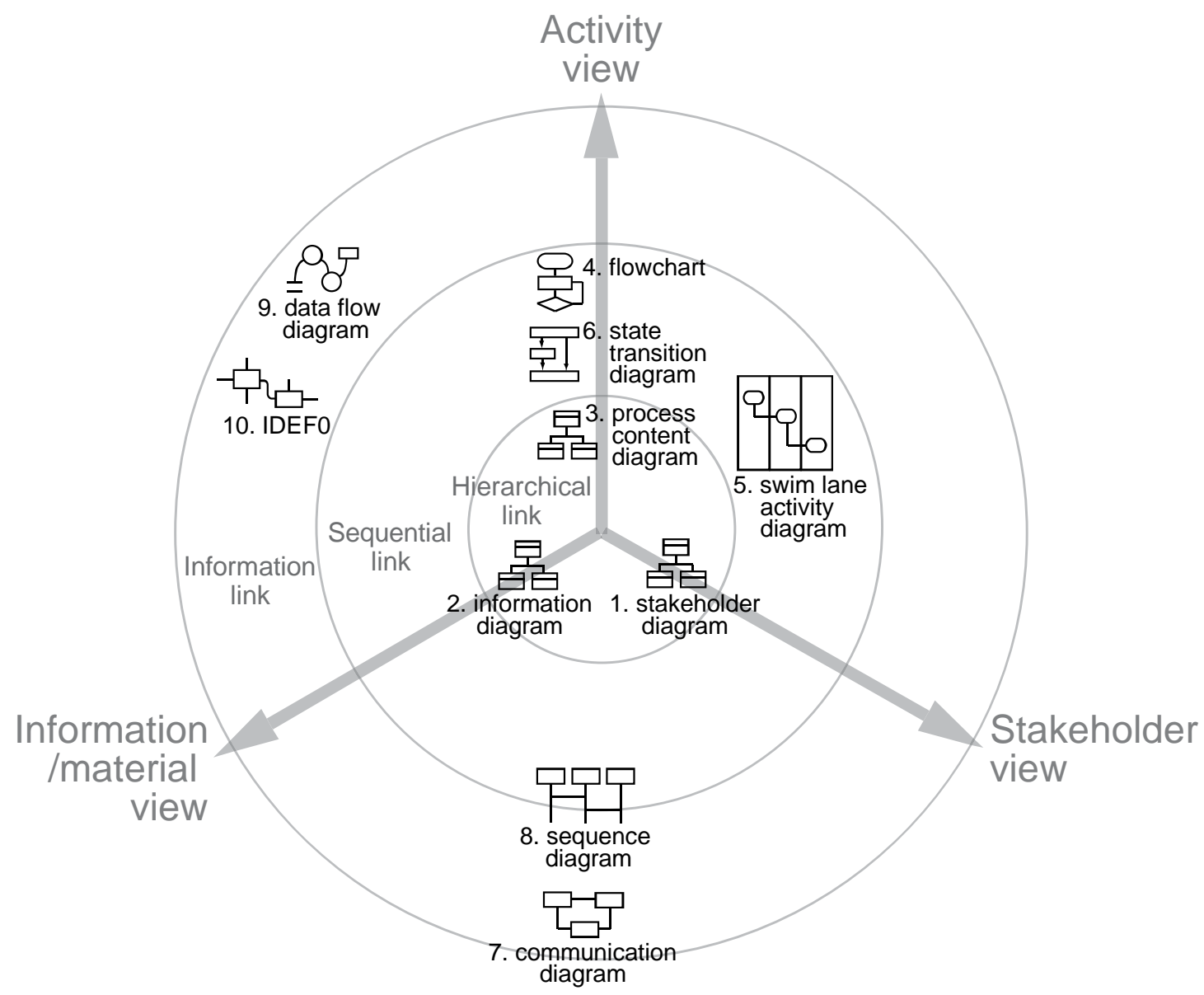

Figure 2. A framework for systems modelling method characterisation 


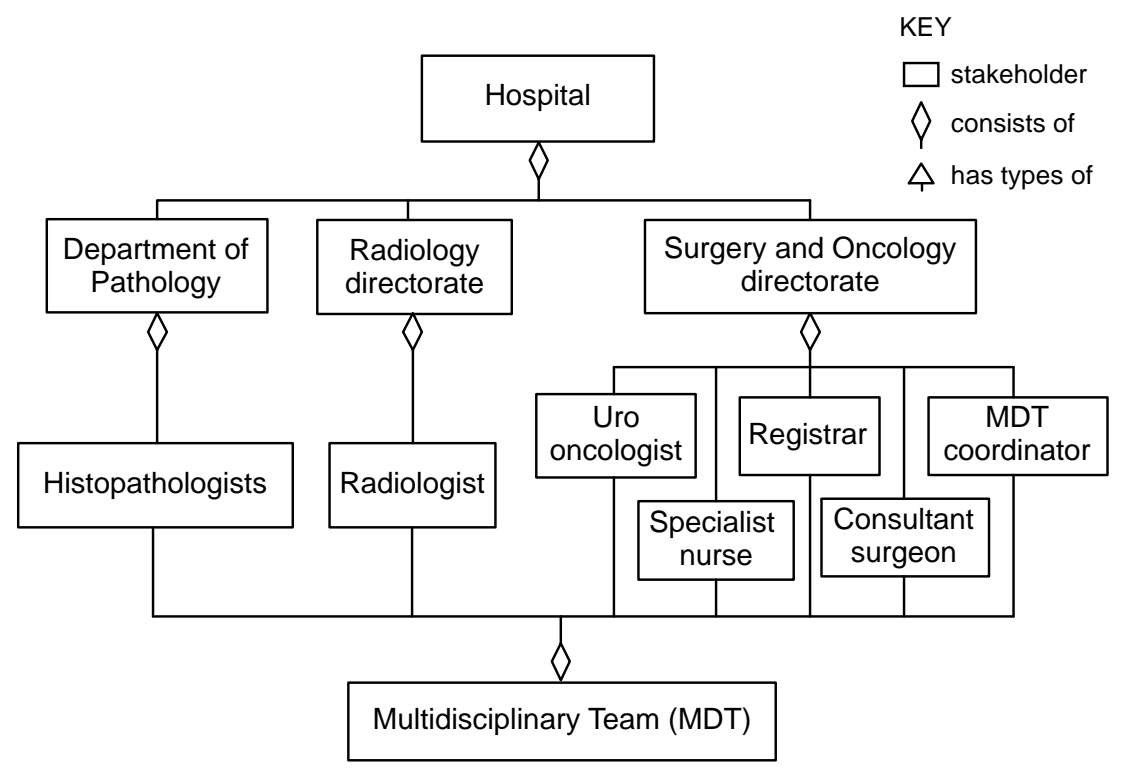

Figure 3. Stakeholder diagram of a prostate cancer diagnostic process

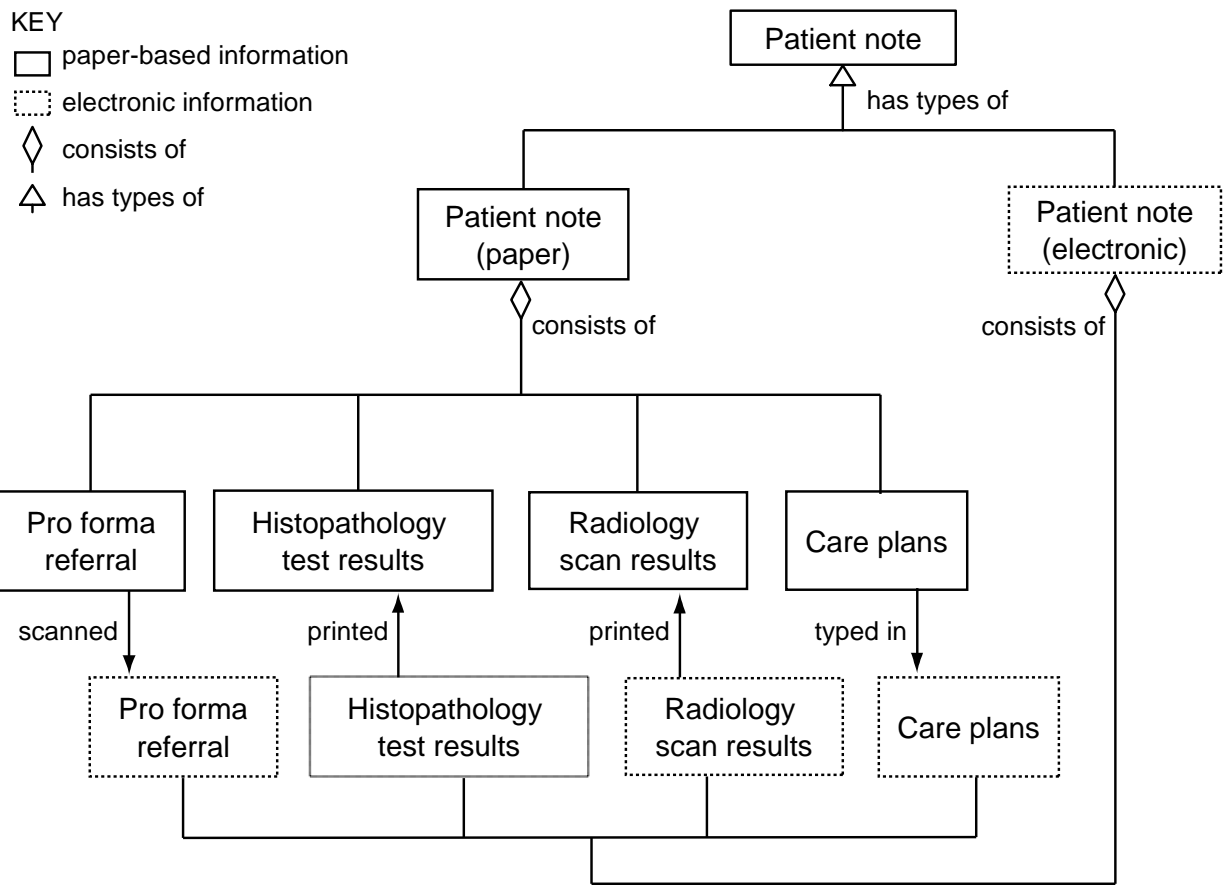

Figure 4. Information diagram of a prostate cancer diagnostic process 


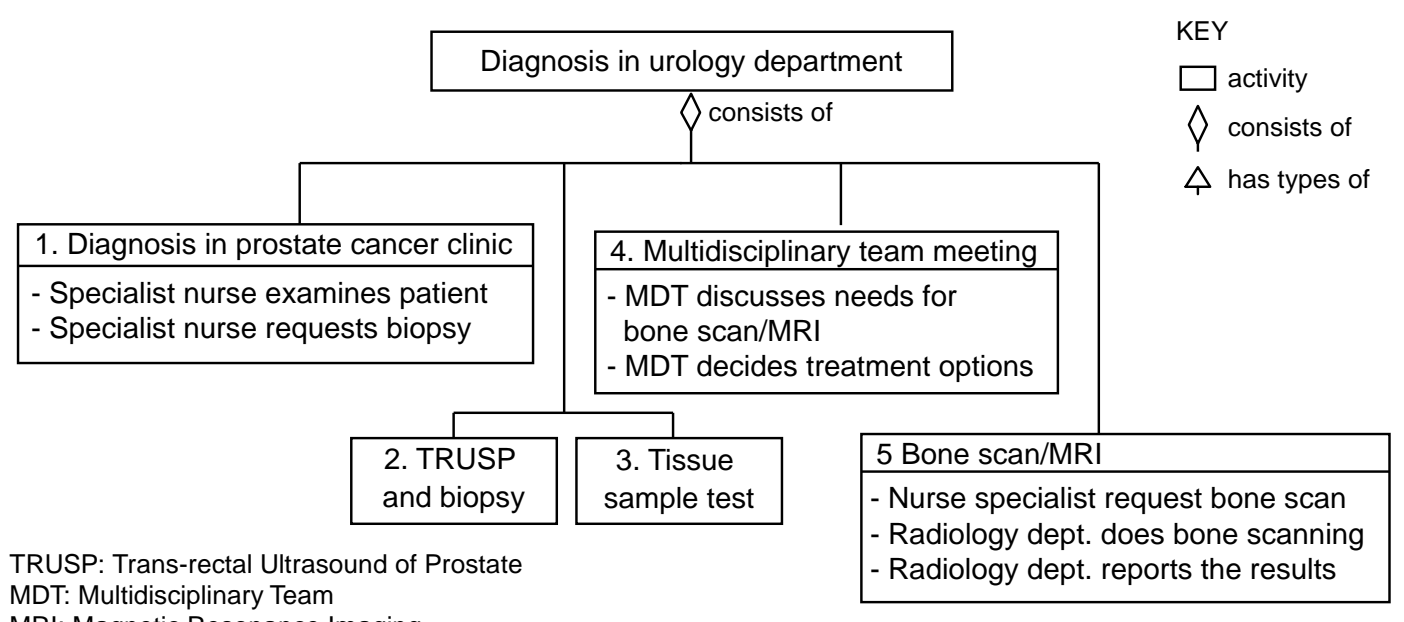

MRI: Magnetic Resonance Imaging

\section{Figure 5. Process content diagram of a prostate cancer diagnostic process}

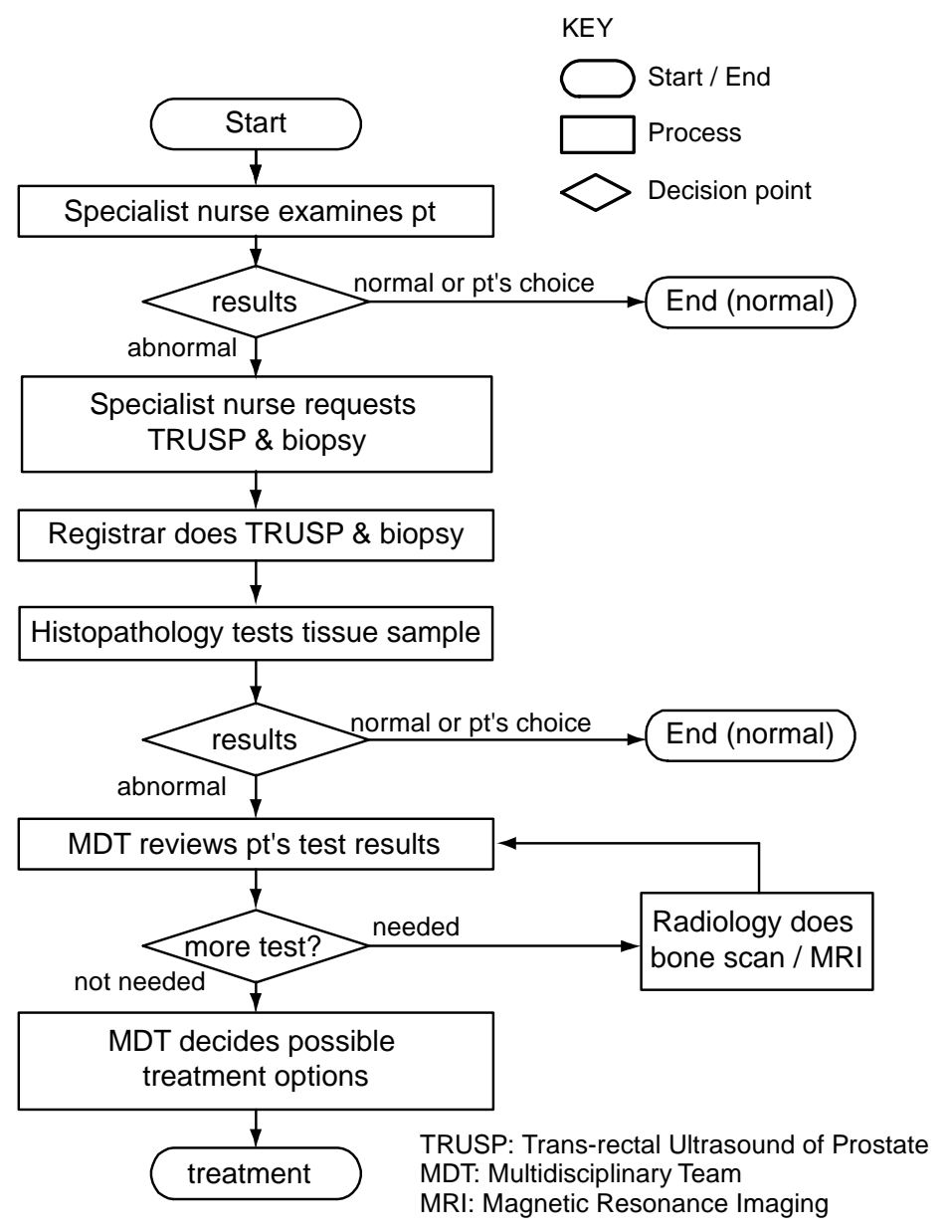

Figure 6. Flowcharts of a prostate cancer diagnostic process 


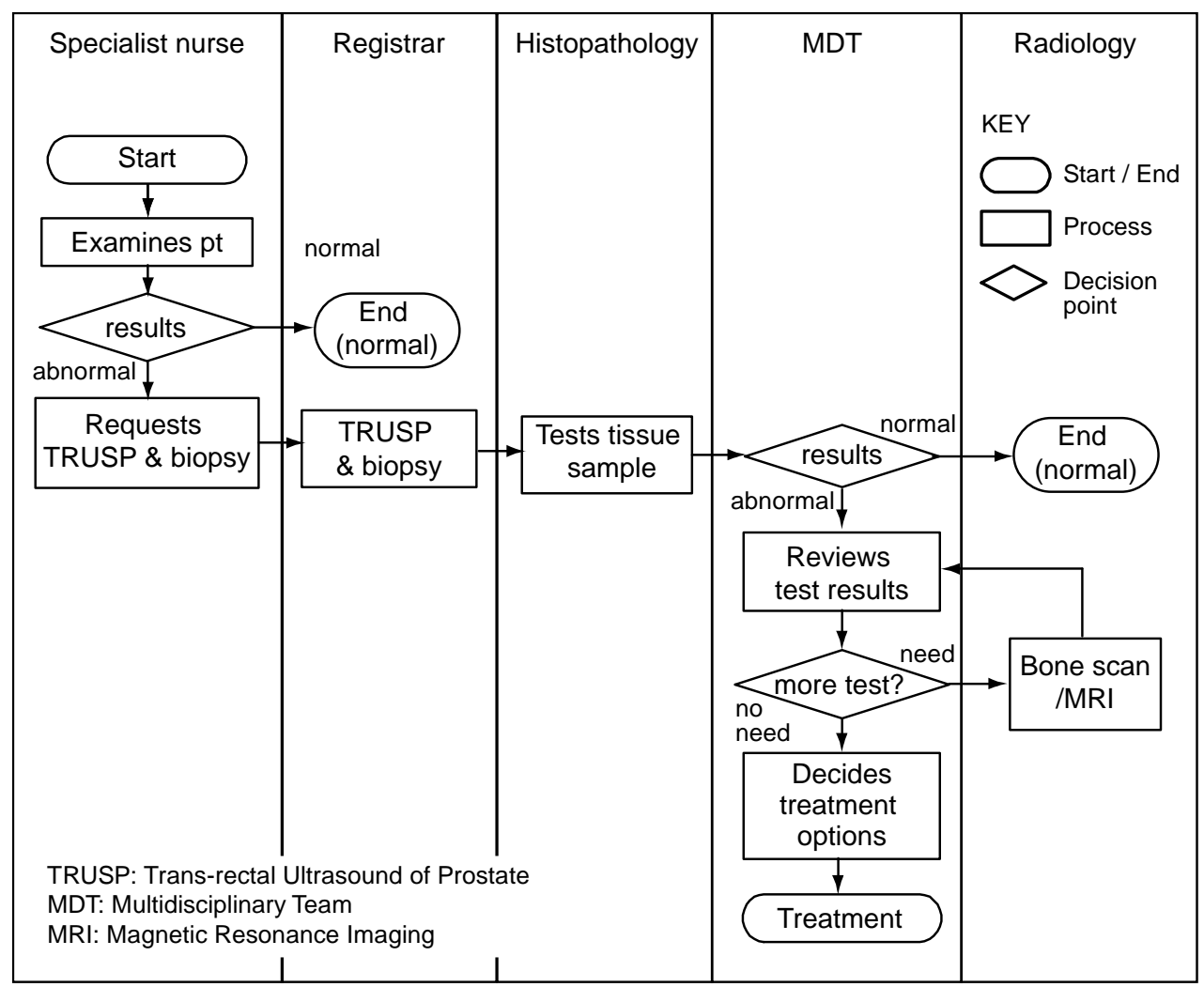

Figure 7. Swim lane activity diagram of a prostate cancer diagnostic process

KEY

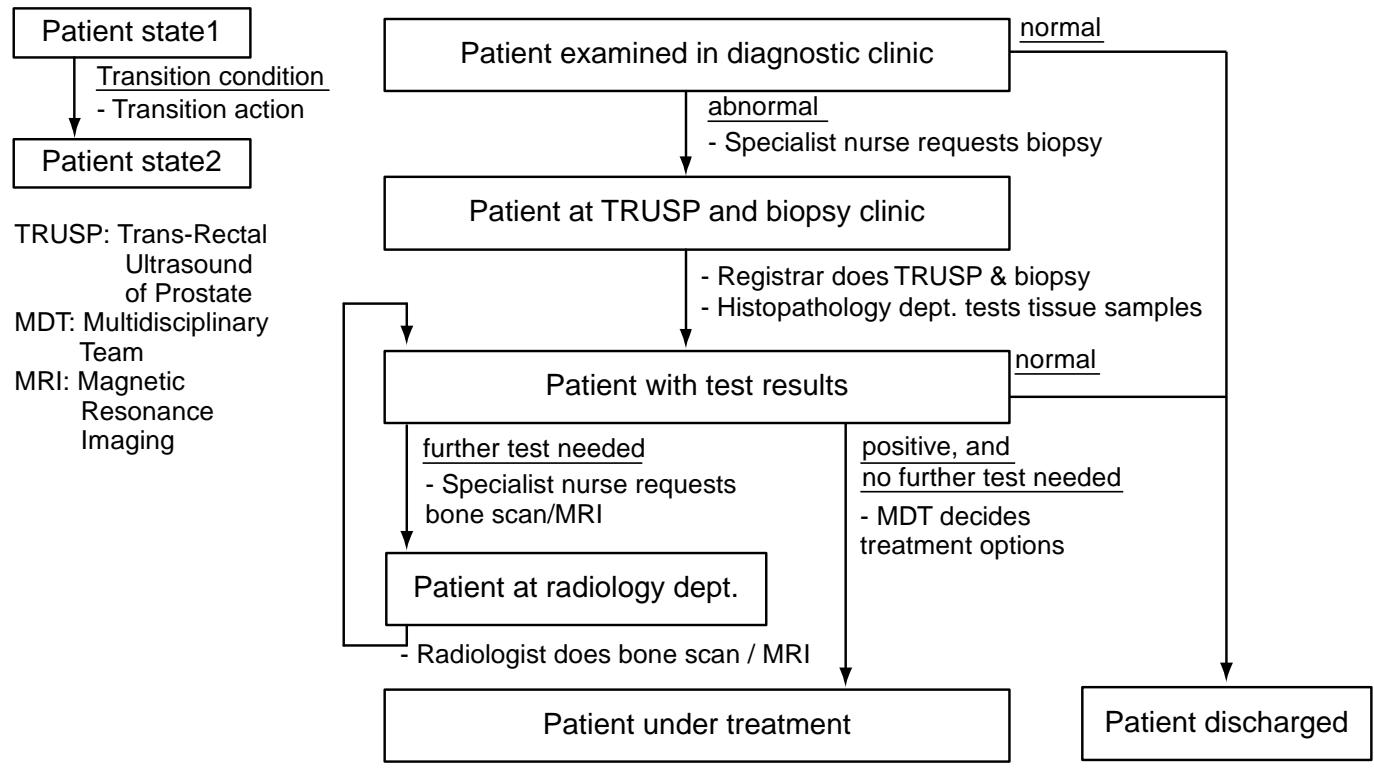

Figure 8. State transition diagram of a prostate cancer diagnostic process 


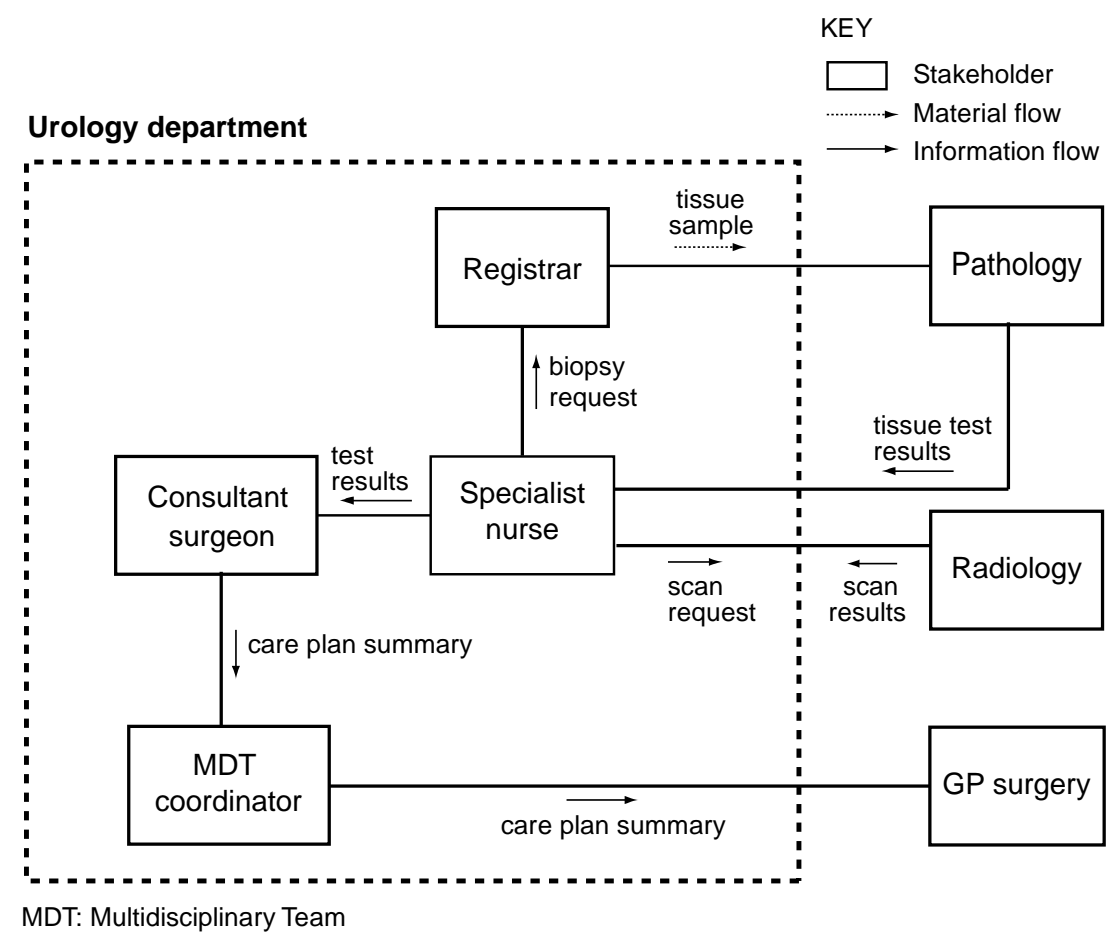

Figure 9. Communication diagram of a prostate cancer diagnostic process

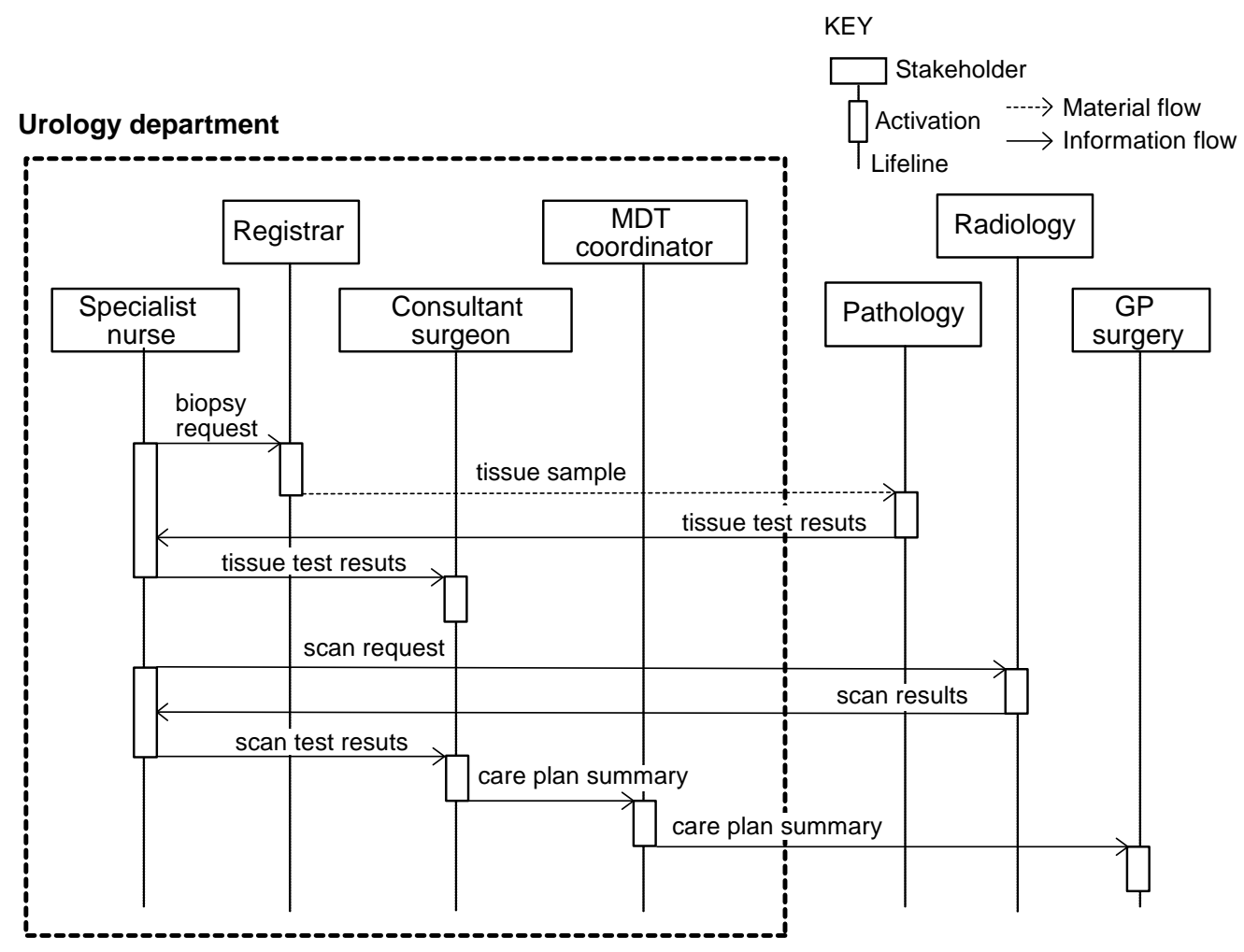

MDT: Multidisciplinary Team

Figure 10. Sequence diagram of a prostate cancer diagnostic process 


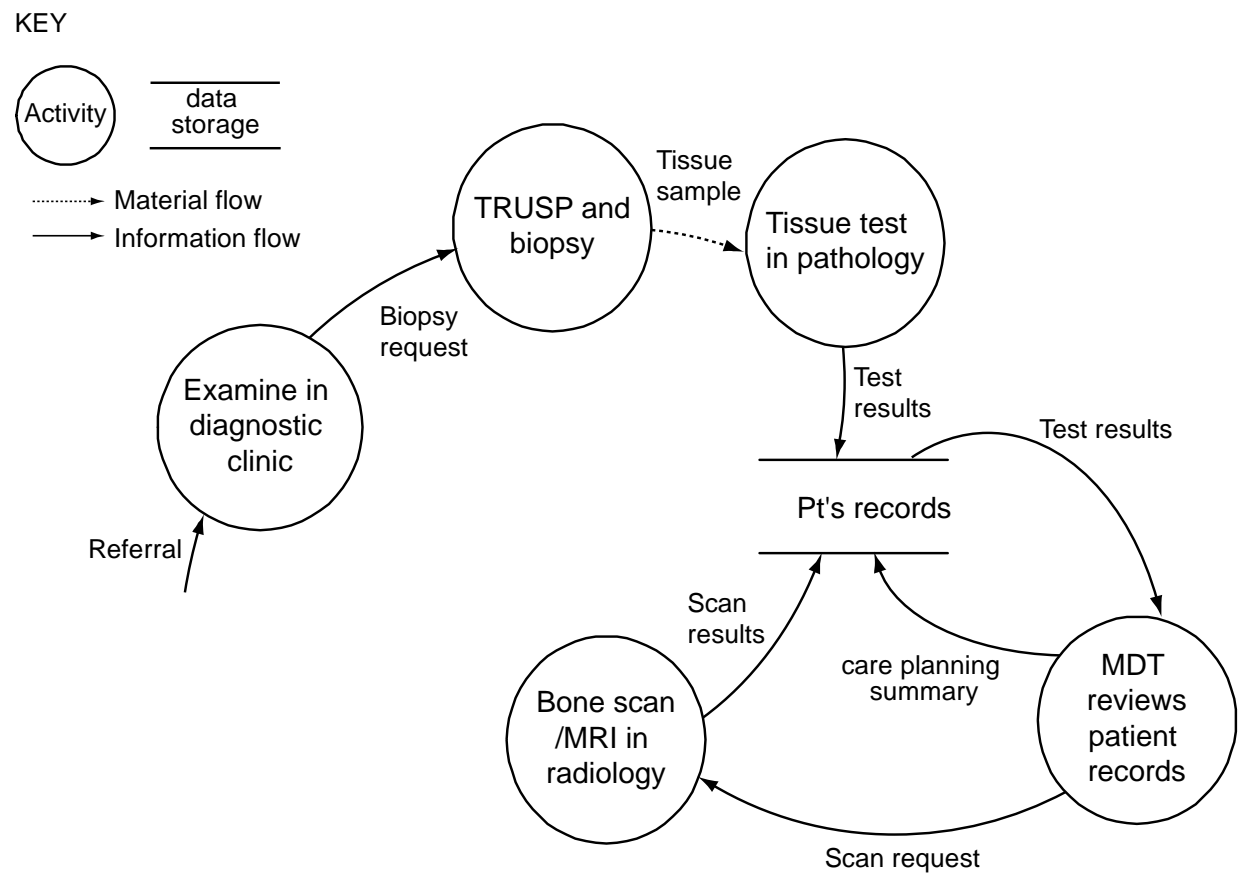

Figure 11. Data flow diagram of a prostate cancer diagnostic process

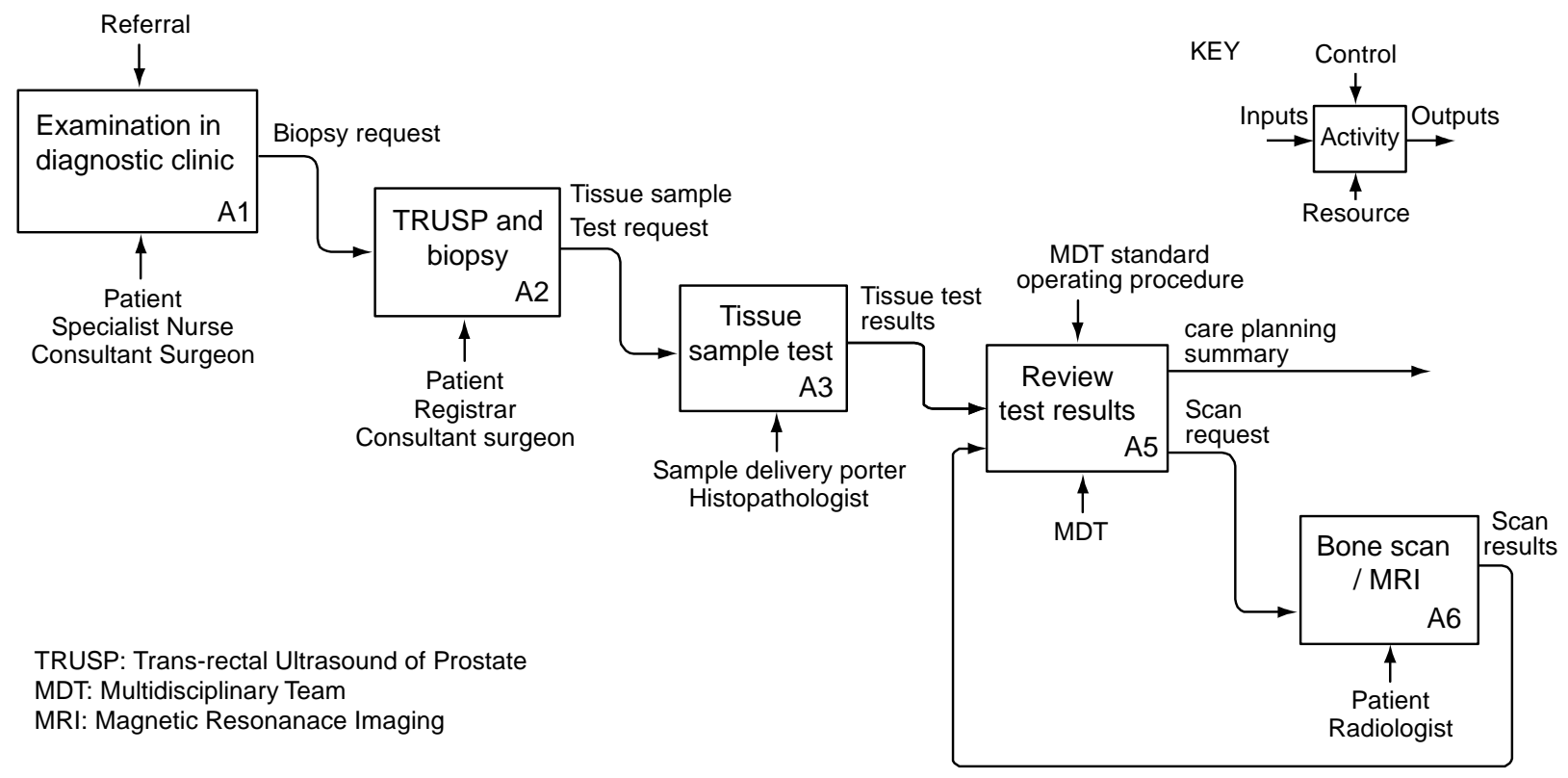

Figure 12. IDEF0 of a prostate cancer diagnostic process 


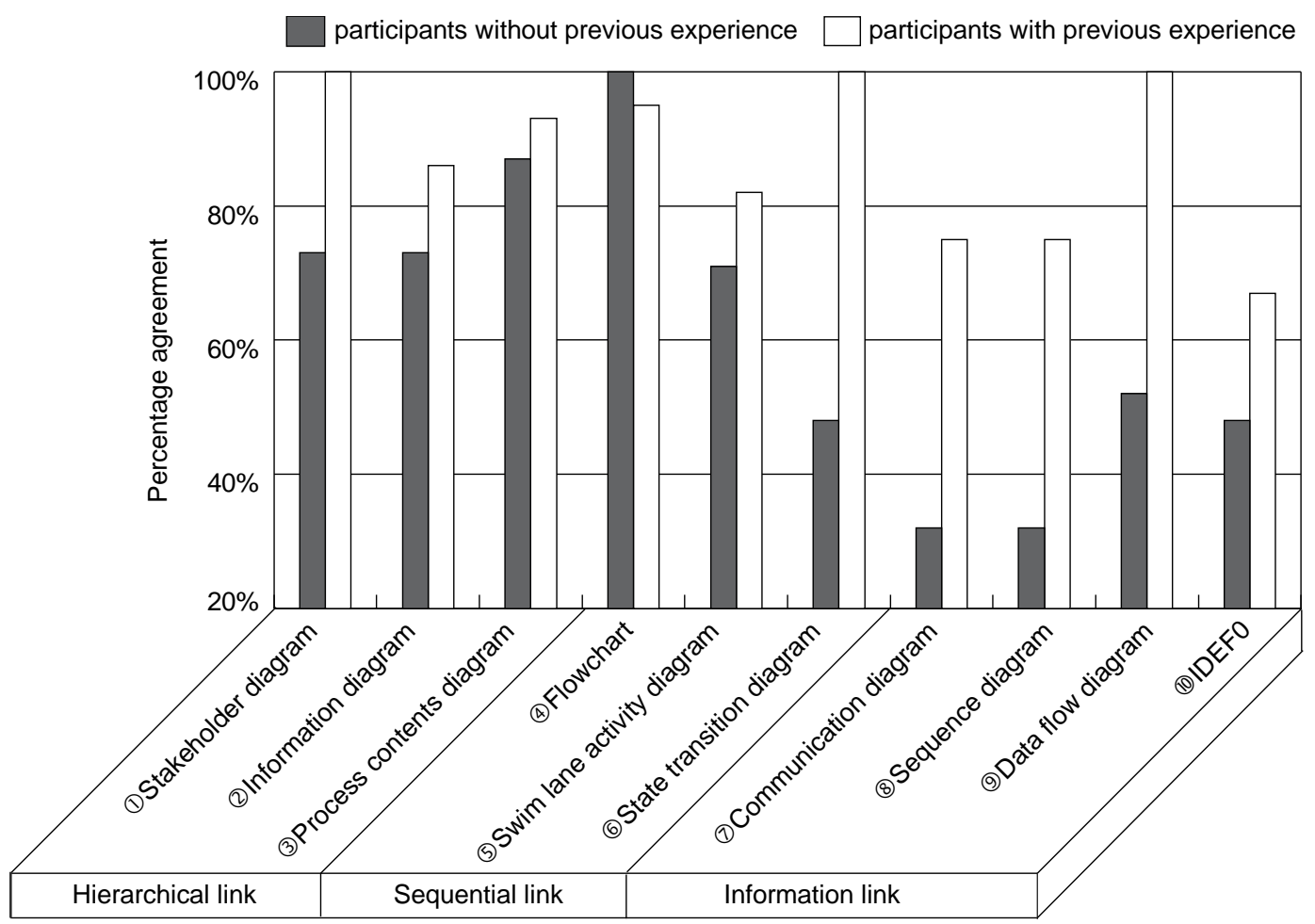

Figure 13. Participants' previous experience with a certain diagram type and their percentage agreement to the 'ease of understanding' of the diagram

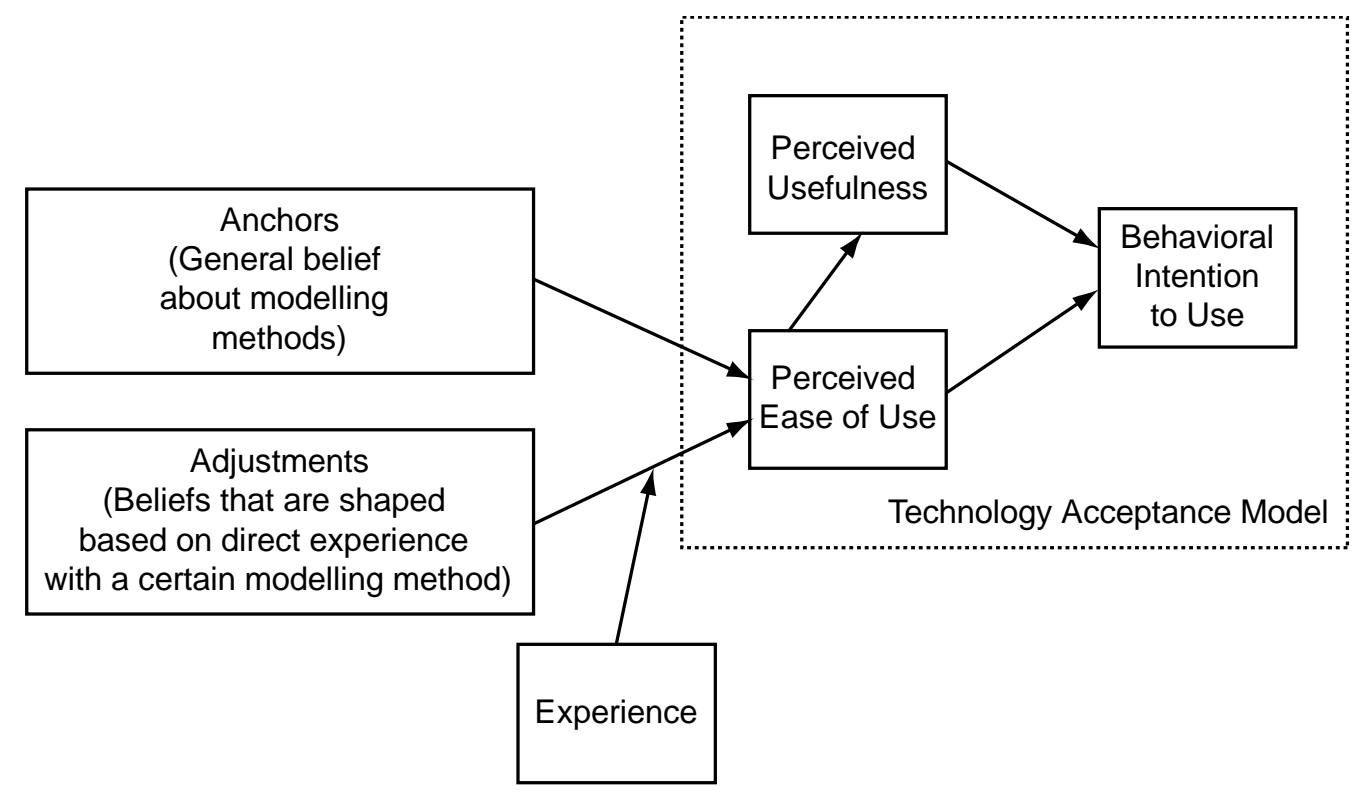

Figure 14. Theoretical framework for the determinants of perceived 'ease of use' (adapted from (Venkatesh 2000)) 